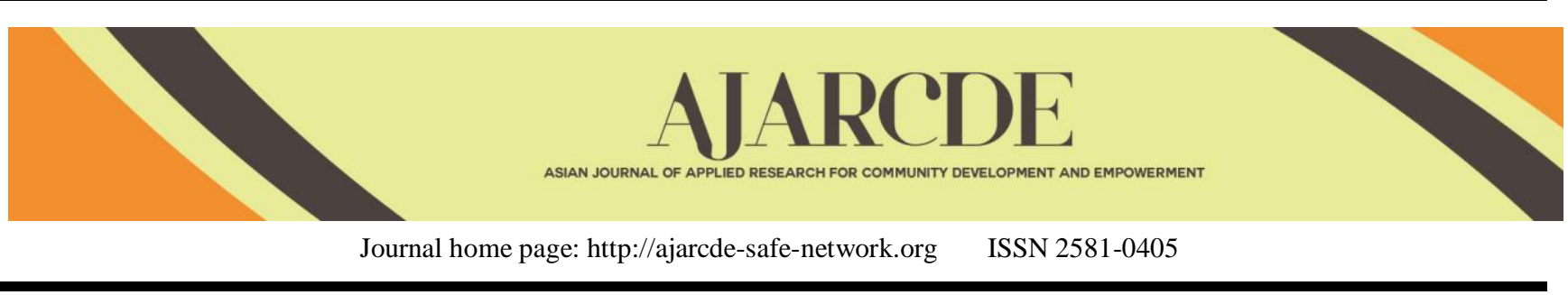

\title{
Appropriate guidelines of Waste Management for Keudchang Sub-district, Maetang District, Chiangmai province, Thailand
}

\author{
S. Sawetrattanakul ${ }^{1}$, S. N. Jansri ${ }^{1}$, N. Tantranont ${ }^{1}$ and W. Setthapun ${ }^{1 *}$ \\ 1. Asian Development College for Community Economy and Technology, Chiang Mai Rajabhat University, Chiang Mai, Thailand \\ *Corresponding author: worajit@cmru.ac.th
}

\section{ARTICLE INFO}

Manuscript History:

Received: 23 August 2019

Final Revision: October 17, 2019

Available Online: December 21, 2019

\section{KEYWORDS}

waste management guidelines, waste disposal, sustainable community

\section{CORRESPONDING AUTHOR}

*E-mail: worajit@cmru.ac.th

\section{A B S T T R A C T}

Waste management is one of the major problems around the world. Governments and global organizations are starting to pay attention to the amount of waste left behind. Thai government drafted the National policies of waste management to manage waste in sustainable ways. Keudchang Sub-district confronts waste management problems due to the increase in the amount of waste, insufficient area for disposal, roadside and riverside litters, an illegal dump of rubbish in forests, and air pollution from waste incineration. The purposes of this research were to study the amount of waste and waste composition in 8 villages of Keudchang Community (KC), and develop appropriate guidelines of waste management. This participatory research collects data from both primary and secondary sources. Primary data sources include interviews and set up a public hearing stage with stakeholders in KC. Secondary data include a documentary of community context, meeting minutes, and other related documents. Qualitative data were analyzed with the content analysis method. The results showed that the KC produce an average of waste to $4,062.02 \mathrm{~kg} / \mathrm{day}$. These wastes could be classified into 4 types including organic waste $(45.83 \%)$, recycle waste $(28.01 \%)$, general waste $(15.55 \%)$, and hazardous waste $(10.60 \%)$ respectively. An individual person at KC produces an average of waste at $0.98 \mathrm{~kg} / \mathrm{day}$. Additionally, the results from conducting a public hearing stage of 8 villages revealed community awareness and solutions for waste management. All people in KC need to sort their wastes properly before disposal in 4 ways. First, organic waste. Each household needs to dig a hole and dump the organic wastes into it. The organic wastes should be managed and separated from other wastes. Second, recycle waste. Various approaches to recycle waste include waste credit bank (WCB), waste volunteer, monthly fee, and self-management. The WCB would be a hub for the communities to make profits and reduce landfill wastes. A waste volunteer would be a volunteer person who buys community wastes and sell them to outsiders. The monthly fee would be an approach where each household pays $70 \mathrm{baht} / \mathrm{month}$ to a garbage collector. Self-management would be another approach where households sort out, eliminate, sell, and manage wastes by themselves. Third, general waste. General waste could be divided into 2 groups as profitable waste and community dumping ground. Profitable waste could be sold to WCB or waste stores by each household. Community dumping ground would be an area allocated to all households for waste disposal. All households would not allow to throw garbage or wastes into other areas, but community dumping ground. Finally, hazardous waste. Hazardous waste would need to dispose of carefully in the trash can located at the office of the village headman. The findings from this study suggested setting up a waste management committee (WMC), as well as defining their roles and responsibilities. Local administrative organizations and community leaders also need to support, supervise, and control community waste management for resource-efficient and sustainable societies

\section{INTRODUCTION}

At present, waste is one of the major problems all over the world. The problem of waste management is getting severe each day [1] due to the unsuitability of waste treatment plant and recycle management. These problems resulted in the environmental pollution and human health. An estimate of waste in the next 31 years or year 2050 is increasing up to 3.4 billion tons (or $70 \%$ ), comparing with the 2.01 billion tons of waste in 2016 [2]. The increasing of waste, burden expenses, and cost of waste management [3] are the challenges of state agencies from developing countries. In 2017, Thailand generated 74,998 tons of waste per day, and 1.13 kilograms of waste per person/day. Waste statistics in the preceding 10-year (2008-2017) shown an increasing in waste of 1.15 percent or about 27.06 million tons every year, according to the population and the build-up areas [4]. Additionally, some part of the community and population are lack of an awareness and participation in waste management. They are 
also lack of knowledge and understanding of waste separation [5]. Kuedchang Sub-district, Maetang District, Chiang Mai Province, is 64 kilometers far from the center area. Kuedchang has a land area of 306.25 square kilometers or 75,654.64 acres [6]. Itis one of the tourist attraction in Chiang Mai province, comprising of 8 villages and good natural resources and environment. There are many attractions such as elephant (elephant camp), Maetang river (Kued river), hill tribes, and other activities such as elephant riding, rafting, zipline, cycling, trekking, hotels and homestays, etc. There are more than one million Thai and foreigners tourists per year visiting Kuedchang. It is now one of the economic areas in Chiang Mai making income to the community and its people. However, there are environmental impacts of tourism such as solid waste increasing, waste burning, as well as dumping waste on public land and river. These problems need urgent solutions to improve the environment. Therefore, this research aims to develop sustainable guidelines of waste management through participatory action research processes from the steakholders for Kuedchang sub-district.

\section{MATERIALS AND METHODS}

This participatory action research collects the data from both primary and secondary sources, in order to study the amount of waste and waste composition in 8 villages of Keudchang Community (KC), and develop appropriate guidelines of waste management. Descriptive statistics and content analysis were used to analyze the data. The flow chart of the research process are shown in Figure 1.

\begin{tabular}{|c|c|}
\hline (1) Community context survey & $\begin{array}{l}\text { Population, culture and social structure } \\
\text { - Environment and ecological }\end{array}$ \\
\hline & Community map and other related information. \\
\hline (2) Focus group & $\begin{array}{l}\text { - Community government officials } \\
\text { - Community leaders and community representatives }\end{array}$ \\
\hline$\downarrow$ & - Amount of waste \\
\hline (3) Waste data collection & - Waste composition \\
\hline$\downarrow$ & - Waste management in KC \\
\hline (4) Waste composition analysis & Waste management guideline \\
\hline$\downarrow$ & \\
\hline (5) Public hearing & Appropriate guidelines of $\mathrm{W} 3$ \\
\hline
\end{tabular}

Figure. 2 Flowchart of the study

\subsection{Community contexts survey}

Data of community contexts derived from government documents, social structure surveys, and ecological surveys. These information include population, culture and social structure, environment and ecological, community map and other related information.

\subsection{Focus group}

Focus group was conducted with 3 persons of community government officials, 8 persons of community leader and 16 persons of community representatives. The goals of this focus group activity were to (1) inform the amount of waste in the community and re-check data from community contexts survey activity (2) understand waste management problem (3) form a team for waste management and (4) develop operation plan.

\subsection{Waste data collection}

Data were collected in 8 communities ( 3 times each). These data included (1) amount of waste (2) waste composition and (3) waste management process. All data were calculated to find the amount of waste per day $(\mathrm{kg})$, average household waste $(\mathrm{kg} /$ household), and average waste weight per person ( $\mathrm{kg} /$ person).
Data of waste generated per person per day from Thai Government would be used to compare with the wasted generated in Kuedchang community. Statistical data analysis would be used for decision making and finding waste management guideline

\subsection{Public hearing of waste management guidelines}

Public hearing would be carried out to analyze the current situation of waste management in the community. All community members were invited to participate in a meeting to listen to problems and ideas of waste management guidelines. They would also be able to suggest or revise guidelines as appropriated for best results.

\section{RESULT AND DISCUSSION}

\subsection{Amount of Waste}

Kuedchang sub-district has a total population of 4,281 people or 2,046 households. Table 1 shows the data of waste in the community. On average, Kuedchang community generated 0.92 $\mathrm{kg}$ of waste, which is less than an average of Thai person of 1.13 $\mathrm{kg}$ [4]. However, village 4, village 1 , and village 6 generated more waste comparing to an average of Thai person. Therefore, appropriate guidelines to reduce and manage waste would be useful to the community for sustainable development.

Table 1. Waste data in Kuedchang Community

\begin{tabular}{ccccrc}
\hline Villages & $\begin{array}{c}\text { Waste Total } \\
\text { Per Day (Kg) }\end{array}$ & $\begin{array}{c}\text { Number of } \\
\text { Households } \\
\text { (Household) }\end{array}$ & $\begin{array}{c}\text { Average Waste } \\
\text { Per Household } \\
\text { (Kg/Household) }\end{array}$ & $\begin{array}{c}\text { Number of } \\
\text { Population } \\
\text { (Person) }\end{array}$ & $\begin{array}{c}\text { Average } \\
\text { Waste } \\
\text { Per } \\
\text { Person } \\
\text { (Kg) }\end{array}$ \\
\hline V1 & $1,363.97$ & 529.00 & 2.58 & 990.00 & 1.38 \\
V2 & $1,175.16$ & 514.00 & 2.29 & $1,243.00$ & 0.95 \\
V3 & 197.50 & 130.00 & 1.52 & 440.00 & 0.85 \\
V4 & 195.20 & 70.00 & 2.79 & 136.00 & 1.44 \\
V5 & 231.36 & 297.00 & 0.78 & 383.00 & 0.60 \\
V6 & 291.57 & 112.00 & 2.60 & 215.00 & 1.36 \\
V7 & 493.61 & 284.00 & 1.74 & 609.00 & 0.81 \\
V8 & 113.64 & 110.00 & 1.03 & 265.00 & 0.43 \\
\hline Total & $4,062.02$ & $2,046.00$ & & $4,281.00$ & \\
\hline Avg. & \multicolumn{7}{c}{2.36} & & 0.92 \\
\hline
\end{tabular}

\subsection{Waste Composition}

Waste Composition in $\mathrm{KC}$ would be classified into 4 types as shown in Figure 2. These are organic waste $(15.55 \%)$, recycle waste $(28.01 \%)$, general waste $(15.55 \%)$, as well as hazardous waste $(10.60 \%)$ respectively. Organic waste comprises of food waste for $44.99 \%$, and leave and branches of tree for $0.85 \%$. Recycle waste includes glass and bottles $(12.71 \%)$, plastic bottles $(4.55 \%)$, paper, document paper, and book $(3.67 \%)$, as well as milk carton, and milk box $(2.48 \%)$ respectively. General waste consists of plastic bag $(15.11 \%)$, foam and polystyrene $(0.45 \%)$. Hazardous waste comprises of diapers $(4.56 \%)$, toilet paper $(4.55 \%)$, sticking plaster/gauze $(0.44 \%)$, insecticide of can spray $(0.24 \%)$, and injection needle $(0.21 \%)$.

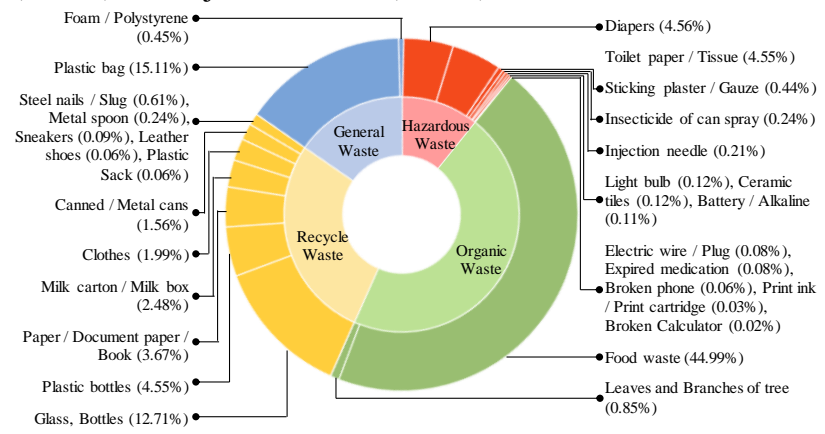

Figure 2. Waste Composition

\subsection{Waste composition analysis}




\subsection{Waste Management Guidelines}

Waste management guidelines were developed from surveys, focus group, waste data analysis, as well as public hearing. Detailed guidelines are shown in Table 2.

Table 2. Appropriate guidelines of Waste Management

\begin{tabular}{ll}
\hline \multicolumn{1}{c}{ Type } & \multicolumn{1}{c}{ Guidelines } \\
\hline Organic & $\begin{array}{l}\text { Organic waste should be managed and separated } \\
\text { Waste } \\
\text { from other wastes. Food waste would be used as } \\
\text { animal food. All households should dig a hole within } \\
\text { their areas. }\end{array}$
\end{tabular}

Recycle Four approaches to recycle waste are:

Waste (1) Waste credit bank (WCB), waste volunteer, monthly fee, and selfmanagement. The WCB would be a hub for the communities to make profits and reduce landfill wastes.

(2) Waste volunteer would be a volunteer person who buy community wastes and sell them to outsiders.

(3) Monthly fee would be an approach where each household pays $70 \mathrm{baht} / \mathrm{month}$ to a garbage collector.

(4) Self-management would be another approach where households sort out, eliminate, sell, and manage wastes by themselves.

General Two groups of general waste are:

Waste (1) Profitable waste, which could be sold to WCB or waste stores

(2) Community dumping ground would be an area allocated to all households for waste disposal. All households would not allow to throw garbage or wastes into other areas, but community dumping ground.

Hazardous Hazardous waste would need to dispose carefully in Waste the trash can located at the office of the village headman. The KC Sub-district Administration Organization should educate people for waste separation and methodically waste collection.

\section{CONCLUSION}

On average, Kuedchang Sub-district generated $0.92 \mathrm{~kg}$ of waste per person per day. These waste could be classified into 4 types including organic waste, recycle waste, general waste, and hazardous waste. Therefore, appropriate guidelines of waste management were developed for environmental sustainability. The findings from this study suggested that the community need to set up waste management committee (WMC), as well as defind their roles and responsibilities. Local administrative organizations and community leaders also need to support, supervise, and control community waste management for resource efficient and sustainable societies

\section{ACKNOWLEDGMENT}

This work is supported by Asian Development College for Community Economy and Technology (adiCET), Chiang Mai Rajabhat University, Thailand. The authors would also like to thank Kuedchang Sub-district Administrative Organization and all participants for providing useful information and offering us to collect data at the communities..

\section{REFERENCE}

[1] Swati A., Sanjay J., and Richa M. (2018). Sustainable Approach towards Solid Waste Management: A Case of TIER II Indian City - Gwalior. Grenze International Journal of Engineering and Technology, July 2018. pp $19-27$.

[2] Silpa Kaza, Lisa Yao, Perinaz Bhada-Tata, and Frank Van Woerden. (2018). What a Waste 2.0 A Global Snapshot of Solid Waste Management to 2050. The Report of World Bank Group. pp 17-25.

[3] Guerrero, L. A., et al. (2013). "Solid waste management challenges for cities in developing countries." Waste management. Vol 33(1): pp 220 - 232.

[4] Pollution Control Department. (2018). Information on indicators of community waste per day. Office of Natural Resources and Environmental Policy and Planning. Ministry of Natural Resources and Environment. [website] http://www.onep.go.th/env_data/2016/01_53/

[5] Kuedmeesook, P. (2017). Participation in the management of community banks refuse Wat Puranawath Thawi Watthana Bangkok (Phase 1). Academic Journal Bangkokthonburi University. Vol 6(2): pp 92 - 101.

[6] Kuedchang Sub-district administration organization. (2019). Kuedchang development plan for 4 year $(2018$ - 2021). Policy and Planning Analysis Section. Office of the Chief Administrator of Sub-district administration organization. pp $2-21$. 